\title{
Vaccine Adjuvants Derivatized from Momordica Saponins I
}

\section{and II}

Pengfei Wang, $*[a]$ Xiong Ding, ${ }^{[a]}$ Hyunjung Kim, ${ }^{[a]}$ Dani Škalamera,${ }^{[a]}$ Suzanne M. Michalek, ${ }^{[b]}$ and Ping Zhang $^{[c]}$

${ }^{\mathrm{a} D e p a r t m e n t ~ o f ~ C h e m i s t r y, ~}{ }^{\mathrm{b}}$ Department of Microbiology, ${ }^{\mathrm{c}}$ Department of Pediatric Dentistry, University of Alabama at Birmingham, $90114^{\text {th }}$ Street South, Birmingham, AL 35294

wangp@uab.edu

Table of Content

Page

\begin{tabular}{|l|l|}
\hline Table of content & $\mathrm{S} 1$ \\
\hline${ }^{1} \mathrm{H}$ NMR spectrum of $\mathbf{3}$ & $\mathrm{S} 2$ \\
\hline${ }^{1} \mathrm{H}$ NMR spectrum of $\mathbf{4}$ & $\mathrm{S} 3$ \\
\hline${ }^{1} \mathrm{H}$ and ${ }^{13} \mathrm{C}$ NMR spectra of $\mathbf{5}$ & $\mathrm{S} 4-5$ \\
\hline${ }^{1} \mathrm{H}$ and ${ }^{13} \mathrm{C}$ NMR spectra of $\mathbf{6}$ & $\mathrm{S6-7}$ \\
\hline
\end{tabular}




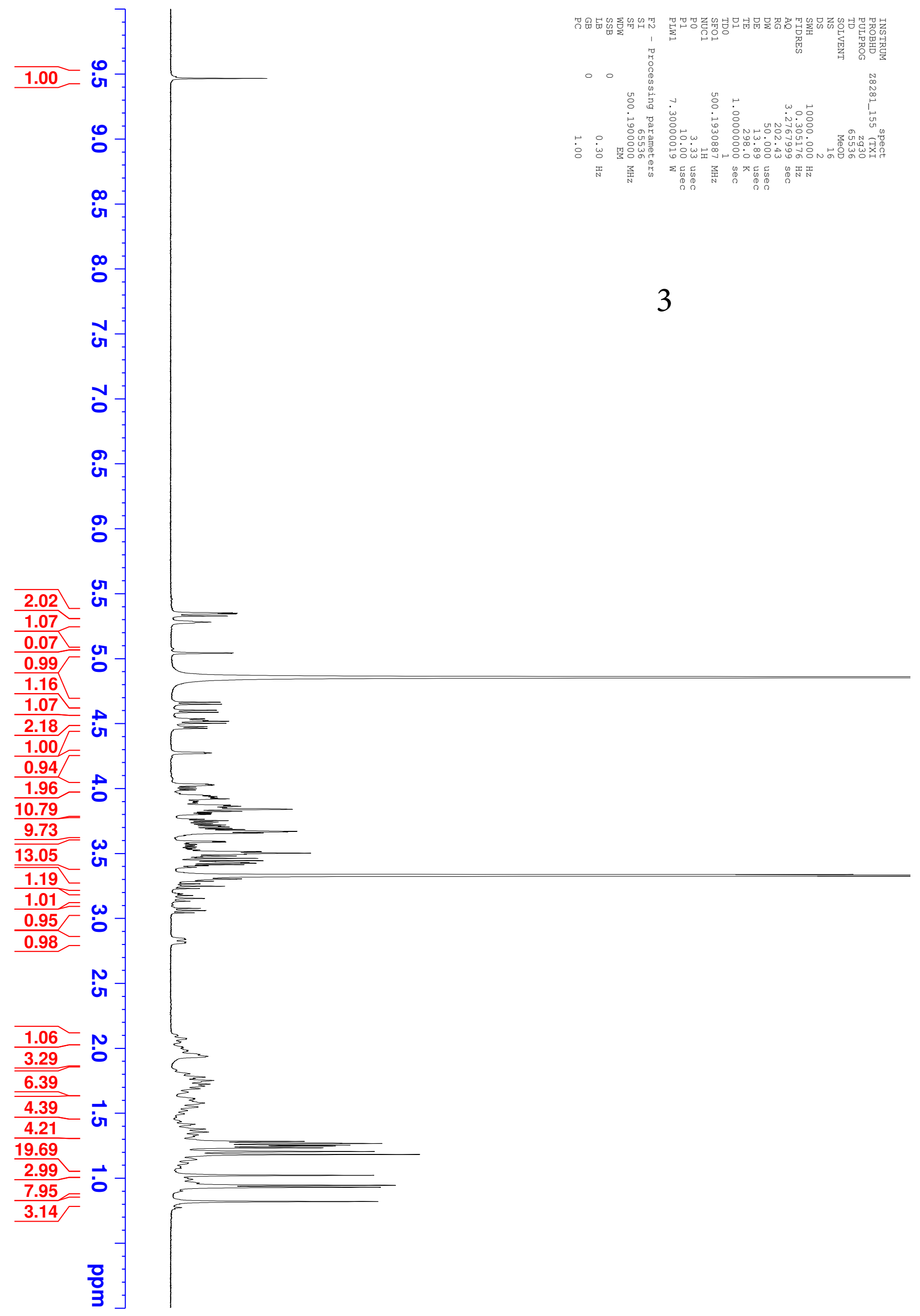




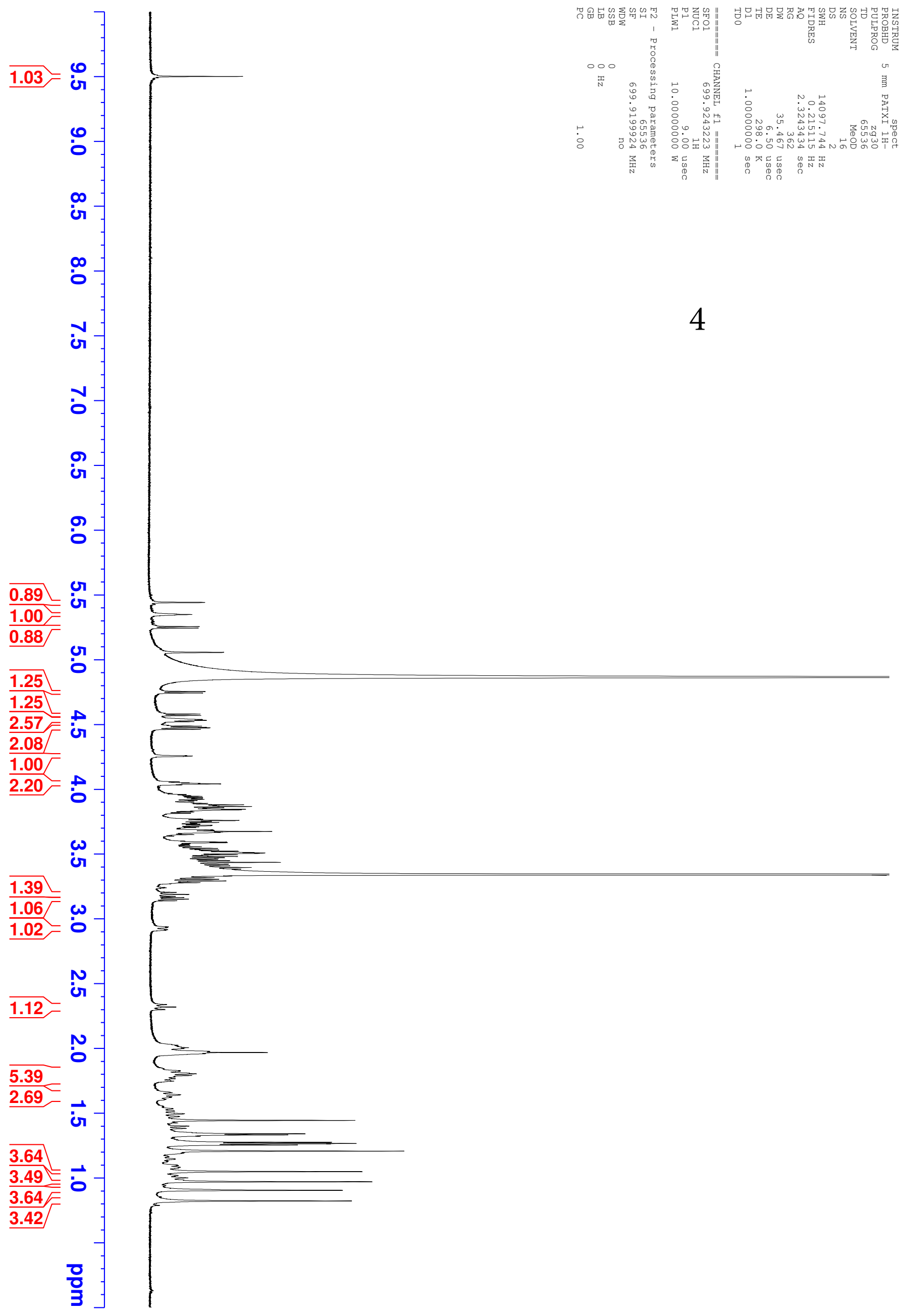




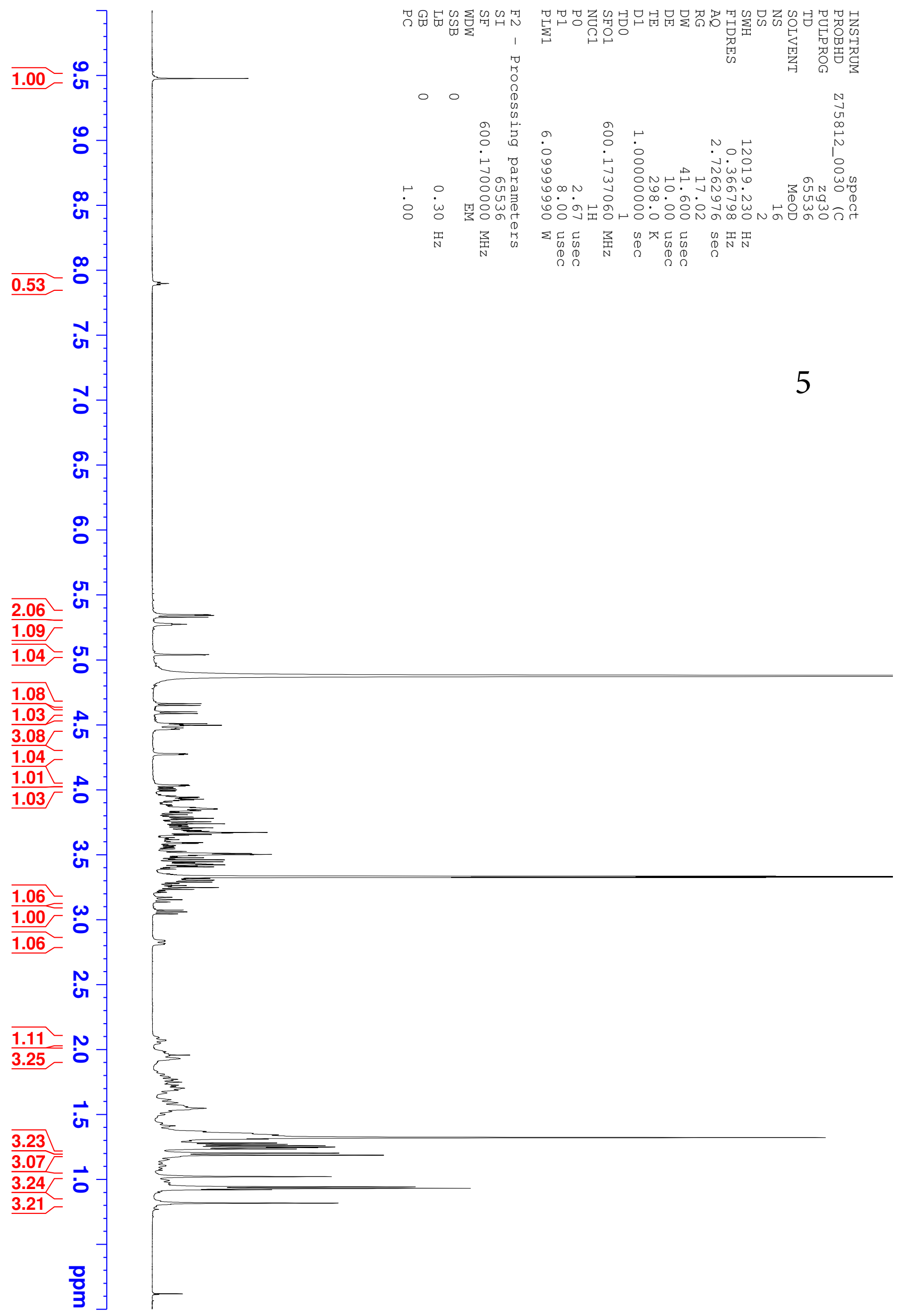




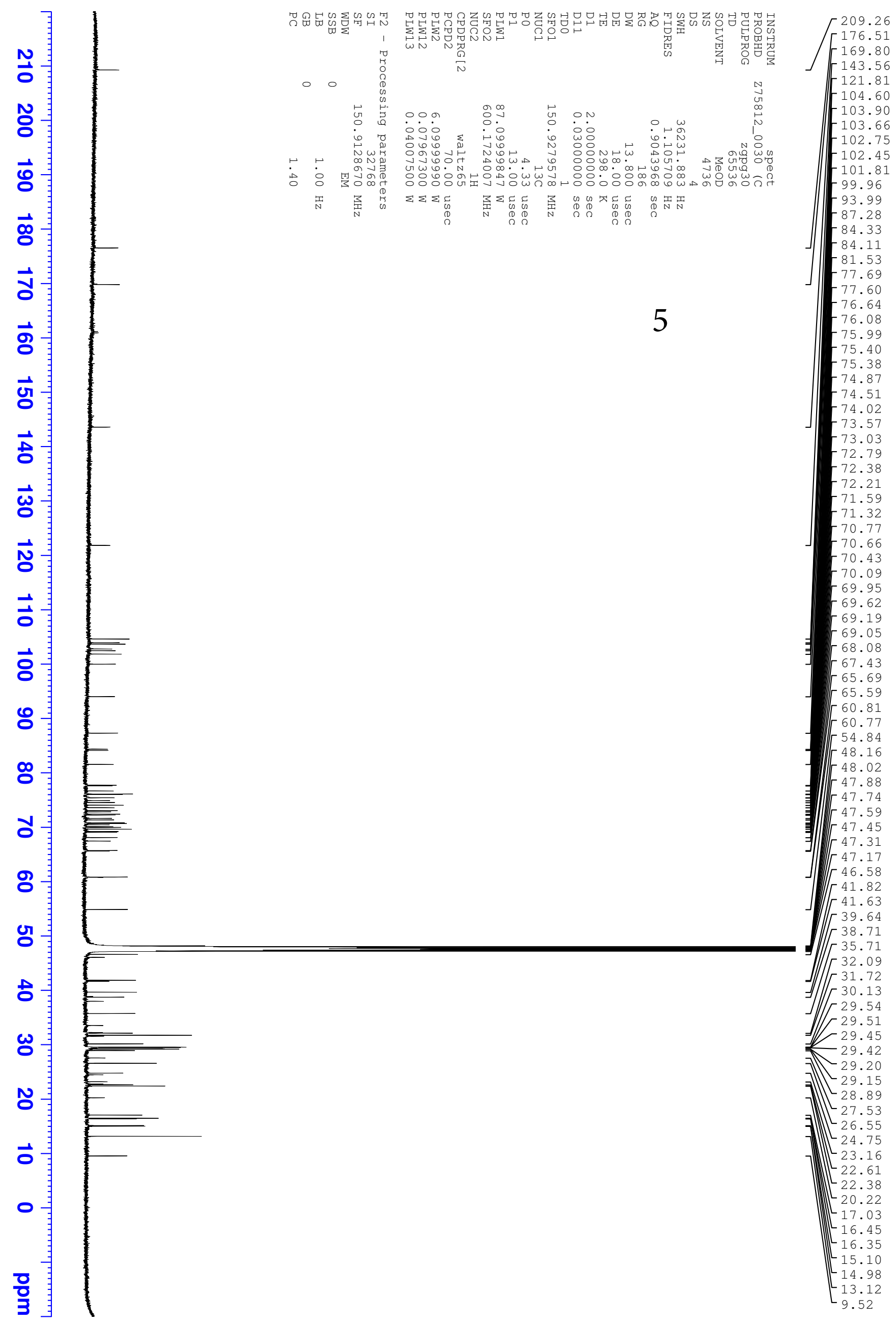









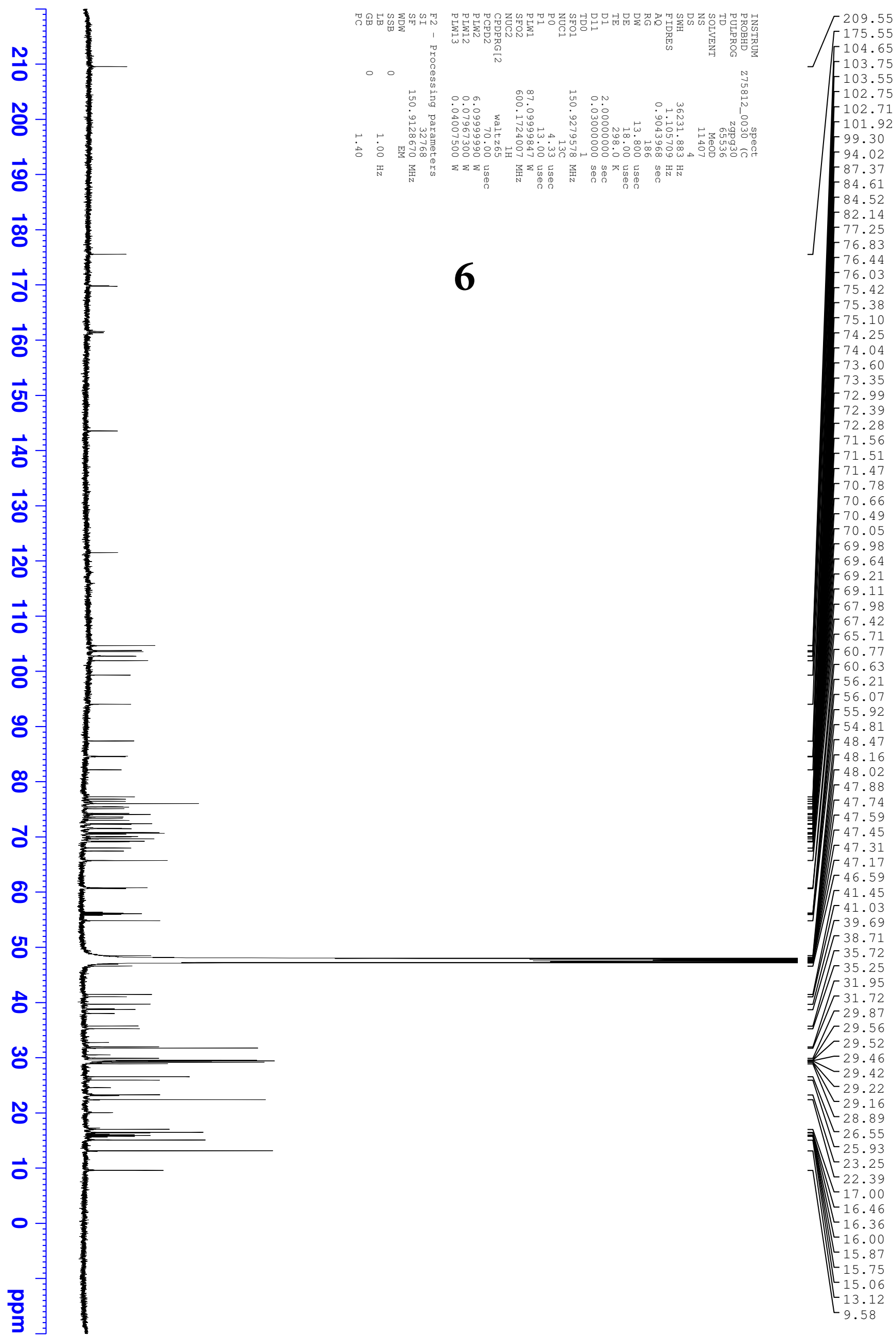

